\title{
LESIONES MEDULARES NO TRAUMÁTICAS: ETIOLOGÍA, DEMOGRAFÍA Y CLÍNICA
}

\author{
Asencio Quintana-Gonzales ${ }^{1, a}$, Rosa Sotomayor-Espichan²,a María Martínez-Romero,a, \\ César Kuroki-García ${ }^{3, a}$
}

\begin{abstract}
RESUMEN
Se realizó un estudio retrospectivo y descriptivo en 210 pacientes hospitalizados con lesión medular del Instituto Nacional de Rehabilitación (INR), Callao-Perú (2000-2006) para conocer la etiología, características clínicas y socio-demográficas de los pacientes con lesiones medulares no traumáticas (LMNT). Se encontró una prevalencia de $27 \%$ para LMNT siendo la edad promedio al inicio de la lesión 32,0 años; siendo varones el 50,5 \%, y el 41,9 \% tuvieron educación secundaría, el nivel de pobreza alcanzó el 90,5\%. Predominó la etiología infecciosa (viral y bacteriana) en 37,6 \%, con un $11,9 \%$ de infección por HTLVI. No obstante ser el INR un centro de referencia, nuestros resultados son preliminares, siendo necesario realizar mayores estudios para proponer estrategias de prevención y control, dado el alto costo del tratamiento integral de rehabilitación en estos pacientes.
\end{abstract}

Palabras clave: Lesiones de la médula espinal; Prevalencia; Etiología (fuente: DeCS BIREME).

\section{NONTRAUMATIC SPINAL CORD INJURY: ETIOLOGY, DEMOGRAPHY AND CLINICS}

\begin{abstract}
We performed a retrospective and descriptive cross-sectional; study in 210 hospitalized patients with spinal cord injury at the National Institute of Rehabilitation (INR), Callao, Peru from 2000-2006. The goal was to describe etiology, and clinical and socio-demographic characteristics of non traumatic spinal cord injuries (LMNT). We found a prevalence of $27 \%$ for LMNT, average age at onset of 32.0 years, male gender $50.5 \%$, and secondary education completed in $41.9 \%$, poverty $90.5 \%$. The infectious etiology (viral and bacterial) was predominant in $37.6 \%$, with 11.9 infected with HTLVI. Although the INR is a reference center, the findings can't be generalized because it isn't a representative sample of the Peruvian population, further studies are necessary to propose strategies for prevention and control, considering the high cost of integral rehabilitation treatment in these patients.
\end{abstract}

Key words: Spinal cord injuries; Prevalence; Etiology (source: MeSH NLM).

\section{INTRODUCCION}

La lesión medular es una de las afecciones más graves y discapacitantes por las grandes limitaciones y complicaciones que se derivan de ella, constituyendo un serio problema de salud pública. El portador de una lesión medular presenta pérdida de función motora de diferentes niveles y grados de extensión, disminución o pérdida de sensibilidad, disfunción vesical, intestinal y sexual; así como severas consecuencias psíquicas, sociales y económicas debido a su situación de discapacidad permanente e irreversible.

No hay buenos registros sobre la incidencia de las lesiones medulares no traumáticas (LMNT) debido a problemas en las definiciones, datos epidemiológicos escasos y atención de estos pacientes por diferentes especialidades. Así, la esclerosis múltiple es catalogada como lesión medular por algunos autores y excluida por otros; se vienen registrando como causas de LMNT

\footnotetext{
Dirección Ejecutiva de Investigación, Docencia y Rehabilitación Integral en Funciones Motoras, Instituto Nacional de Rehabilitación. Callao, Perú.

Departamento de Investigación, Docencia y Rehabilitación Integral en Lesiones Medulares, Instituto Nacional de Rehabilitación. Callao, Perú.

Departamento de Investigación, Docencia y Rehabilitación Integral en Unidad Motora y Dolor, Instituto Nacional de Rehabilitación. Callao, Perú.

a Médico Rehabilitador
}

Recibido: 12-08-11 Aprobado: 09-11-11 
enfermedades crónicas progresivas como esclerosis múltiple, espondilosis cervical y esclerosis lateral amiotrófica. De las LMNT en el University of Rochester Medical Center, el $45 \%$ fueron causadas por tumores (primarios y metastásicos), otras causas incluyeron insuficiencia vascular, osteomielitis, hernia del núcleo pulposo y cambios degenerativos que causaron compresión del cordón espinal (1).

En España se encontró como causas médicas el 18,5 \% (2). En Bangladesh (India) el mal de Pott alcanzó el $28 \%$, los tumores $21 \%$ y la mielitis transversa $9 \%{ }^{(3)}$.

En un estudio sobre frecuencia de daños trazadores (es decir, deficiencia o enfermedad que se usa para medir la situación de discapacidad en la población y la capacidad operativa del establecimiento en relación al tratamiento rehabilitador) en pacientes hospitalizados en el Instituto Nacional de Rehabilitación (INR) entre enero y diciembre de 2004, utilizando el Clasificador Internacional de Enfermedades versión 10, se informó traumatismo de la médula espinal en $68,5 \%$ y otras enfermedades de la médula espinal (no traumáticas) en $31,5 \%$, de las cuales el $26,8 \%$ correspondió a causas infecciosas, $24,4 \%$ enfermedades del desarrollo, 22,0 \% degenerativas, 12,2 \% neoplásicas, $9,8 \%$ vasculares y otras $4,9 \%{ }^{(4)}$.

Clínicamente las enfermedades de la médula espinal suelen cursar con dolor, alteración motora, sensitiva y esfinteriana. Estas manifestaciones se combinan de forma diferente según el síndrome clínico, dependiendo del tipo y nivel de lesión. La estrategia diagnóstica está en función de la forma de presentación; ante un síndrome medular agudo debe sospecharse alteración compresiva, traumática, inflamatoria o vascular, y practicarse estudios complementarios urgentes como la resonancia magnética (RMN) que ofrece mayor información en compresiones medulares, mielitis y enfermedades vasculares y el estudio del líquido cefalorraquídeo es útil en las enfermedades inflamatorias e infecciosas ${ }^{(5)}$.

Habitualmente, los aspectos sociodemográficos relacionados a la LMNT como grado de instrucción, procedencia, ocupación, situación socioeconómica, etc. no son informados, de ahí la trascendencia del presente estudio que nos permite conocer estos aspectos importantes para la inclusión socio-laboral de la persona con LMNT.

El objetivo del estudio fue conocer la etiología, características clínicas y socio-demográficas de los pacientes hospitalizados de un servicio del INR con el diagnóstico de LMNT durante el período 2000-2006.

\section{EL ESTUDIO}

Se realizó un estudio descriptivo y retrospectivo en pacientes hospitalizados con LMNT en un servicio del INR entre los años 2000-2006. Se incluyeron pacientes nuevos con diagnóstico de LMNT en base al CIE-10, según el informe médico del hospital de procedencia, con etiología consignada y corroborada con RMN, exámenes de laboratorio bacteriológico y viral, estudio radiográfico o respuesta al tratamiento. Se utilizó el registro de ingresos del sistema de información en discapacidad del instituto (INR-DIS) del cual se obtuvo el listado de historias clínicas de los pacientes que constituyeron la población de estudio, a través de la Oficina de Estadística e Informática del INR.

De los 248 pacientes con LMNT identificados durante el período de estudio, 210 cumplieron con los criterios mencionados y los datos completos. Fueron excluidos del estudio pacientes que no contaron con informe médico, reingresos hospitalarios e historias clínicas incompletas.

Se obtuvo información de las historias clínicas estandarizadas mediante una ficha de recolección de datos elaborada para el estudio, que incluyó: datos de filiación (sexo, lugar de procedencia, grado de instrucción, estado civil, ocupación, estabilidad de empleo), nivel socioeconómico (Método de la Línea de Pobreza), datos de la enfermedad actual (edad, lugar y fecha de inicio de la lesión), etiología (infecciosa, neoplásica, del desarrollo, vascular, degenerativa, metabólica, idiopática, iatrogénica, neurológica) ${ }^{(6)}$, características clínicas de la lesión según la clasificación ASIA para nivel (cervical, dorsal, lumbar y sacro) y tipo (A: ausencia completa de función sensitiva o motora; B: lesión incompleta, hay sensibilidad pero no control motor; C: sensibilidad y función motora conservada, pero la musculatura es no funcional; D: los músculos son funcionales en un $75 \%$; E: la sensibilidad y fuerza presentan una recuperación casi total) ${ }^{(7)}$ y tono muscular al ingreso.

Para el análisis de los datos se utilizaron porcentajes, medidas de tendencia central y tablas de doble entrada para relacionar variables. Los datos se procesaron con el programa SPSS versión 18. Para realizar el estudio se contó con la aprobación de la Oficina de Apoyo a la Investigación y Docencia Especializada y del Comité de Investigación Institucional.

\section{HALLAZGOS}

La prevalencia de LMNT para el período de estudio en los pacientes hospitalizados fue del $27 \%$. En la Tabla 1 se 
Tabla 1. Características demográficas según etiología no traumática en pacientes hospitalizados del INR (2000-2006).

\begin{tabular}{|c|c|c|c|c|c|c|}
\hline CARACTERÍSTICAS & Infecciosa & Degenerativa & Neoplásica & Del desarrollo & Otros & TOTAL \\
\hline \multicolumn{7}{|l|}{ Sexo } \\
\hline Masculino & $36(45,6)$ & $25(75,8)$ & $11(37,9)$ & $14(70,0)$ & $20(40,8)$ & $106(50,5)$ \\
\hline Femenino & $43(54,4)$ & $8(24,2)$ & $18(62,1)$ & $6(30,0)$ & $29(59,2)$ & $104(49,5)$ \\
\hline \multicolumn{7}{|l|}{ Estado civil } \\
\hline Soltero & $28(35,4)$ & $7(21,2)$ & $14(48,3)$ & $5(25,0)$ & $17(34,7)$ & $71(33,8)$ \\
\hline Casado & $25(31,6)$ & $22(66,6)$ & $6(20,7)$ & $1(5,0)$ & $22(44,9)$ & $76(36,2)$ \\
\hline Otro & $26(33,0)$ & $4(12,2)$ & $9(31,0)$ & $14(70,0)$ & $10(20,4)$ & $63(30,0)$ \\
\hline \multicolumn{7}{|l|}{ Región geográfica } \\
\hline Costa & $68(86,1)$ & $29(87,9)$ & $24(82,8)$ & $17(85,5)$ & $44(89,8)$ & $182(86,7)$ \\
\hline Sierra & $10(12,7)$ & $4(12,1)$ & $4(13,8)$ & $3(15,0)$ & $5(10,2)$ & $26(12,4)$ \\
\hline Selva & $1(1,2)$ & - & $1(3,4)$ & - & - & $2(0,9)$ \\
\hline \multicolumn{7}{|l|}{ Grado de instrucción } \\
\hline Sin instrucción & - & - & $2(6,9)$ & $1(5,0)$ & $1(8,3)$ & $4(1,9)$ \\
\hline Primaria & $19(24,1)$ & $13(39,4)$ & $5(17,3)$ & $8(40,0)$ & $8(16,3)$ & $53(25,2)$ \\
\hline Secundaria & $42(53,2)$ & $8(24,2)$ & $11(37,9)$ & $9(45,0)$ & $18(36,8)$ & $88(41,9)$ \\
\hline Superior & $18(22,7)$ & $12(36,4)$ & $11(37,9)$ & $2(10,0)$ & $22(38,6)$ & $65(31,0)$ \\
\hline \multicolumn{7}{|l|}{ Ocupación } \\
\hline Ama de casa & $15(19,0)$ & $4(12,1)$ & $7(24,1)$ & - & $10(20,4)$ & $36(17,1)$ \\
\hline Estudiante & $20(25,3)$ & $1(3,0)$ & $7(24,1)$ & $18(90,0)$ & $7(14,3)$ & $53(25,2)$ \\
\hline Trabajador & $38(48,1)$ & $20(60,6)$ & $14(48,3)$ & - & $27(55,1)$ & $99(47,2)$ \\
\hline Otros & $6(7,6)$ & $8(24,3)$ & $1(3,5)$ & $2(10,0)$ & $2(10,2)$ & $22(10,5)$ \\
\hline \multicolumn{7}{|l|}{ Nivel socioeconómico } \\
\hline Pobre extremo & $45(57,0)$ & $15(45,5)$ & $16(55,2)$ & $10(50,0)$ & $26(53,1)$ & $112(53,4)$ \\
\hline Pobre no extremo & $27(34,2)$ & $13(39,4)$ & $11(37,9)$ & $7(35,0)$ & $20(40,8)$ & $78(37,1)$ \\
\hline No pobre & $7(8,8)$ & $5(15,1)$ & $2(6,9)$ & $3(15,0)$ & $3(6,1)$ & $20(9,5)$ \\
\hline
\end{tabular}

Nota: los valores entre ( ) representan los porcentajes.

muestran las características generales de los pacientes. No hubo predominio según sexo ni estado civil, el 61,9\% estaban en Lima cuando iniciaron su enfermedad, y $24,8 \%$ en el resto de la costa.

El 35,7\% tenía empleo estable (33,3 \% independiente y $66,7 \%$ dependiente), $11,4 \%$ eventual y $52,9 \%$ no trabajaba. La gran mayoría de los pacientes fueron pobres según la clasificación del INEI (53,4 \% pobres extremos y $37,1 \%$ pobres no extremos).

El $37,6 \%$ de los pacientes con LMNT presentaron etiología infecciosa (24,3\% virales y $13,3 \%$ bacterianas); entre ellas, la mielitis transversa viral y HTLV I alcanzaron 11,9 y $11,0 \%$ respectivamente; y en las bacterianas el $11 \%$ estuvo asociado a tuberculosis. En la etiología degenerativa predominaron la estenosis espinal y hernia del núcleo pulposo con $14 \%$. En la etiología neoplásica no hubo predominio de ninguna enfermedad. En las del desarrollo, el total estuvo constituido por espina bífida-mielomeningocele. En las vasculares predominaron las malformaciones arteriovenosas con $94,7 \%$. En las idiopáticas la siringomielia alcanzó el 5,2 \%; como se ve en la Tabla 2.

Respecto a las características clínicas $66,2 \%$ de los pacientes tuvieron 40 años o menos al inicio de la lesión, $64,3 \%$ de las lesiones fueron a nivel torácico, el
$24,8 \%$ fueron lesiones medulares completas (del tipo A según la clasificación ASIA), y de las incompletas la más frecuente fue del tipo $C$ (sensibilidad y función motora conservada, pero la musculatura es no funcional) en un $38,6 \%$. El 79,0 \% tuvieron tono muscular espástico y el 21,0 \% flácido; como está descrito en la Tabla 3.

Se observó que el 54,4 \% de los pacientes con etiología infecciosa y $62,1 \%$ con etiología neoplásica fueron de sexo femenino mientras que $75,8 \%$ con etiología degenerativa fueron de sexo masculino; el inicio de la lesión para las diferentes etiologías fue predominantemente en la costa; solo el 1,9 \% no tenía ningún grado de instrucción. En las diferentes etiologías predominó el grupo de trabajadores según OIT y dentro de ellos los pacientes con trabajo dependiente en todas las etiologías. En el estudio, entre los trabajadores predominaron los pacientes con trabajo dependiente en todas las etiologías. Asimismo el nivel socioeconómico de pobreza (pobre extremo y pobre no extremo) fue el mayor con 91,2 \% para la etiología infecciosa, 84,9 \% etiología degenerativa y 93,1\% etiología neoplásica. El 68,4\% de los pacientes con etiología infecciosa y el 72,4\% neoplásica iniciaron la lesión antes de los 41 años.

Al analizar la etiología en relación a los resultados clínicos se encontró que $74,7 \%$ de los pacientes con 
Tabla 2. Etiología de las LMNT en pacientes hospitalizados del INR (2000-2006).

\begin{tabular}{|c|c|c|}
\hline Etiología & $\mathbf{N}$ & $(\%)$ \\
\hline$\overline{\text { Viral }}$ & 51 & $(24,3)$ \\
\hline Mielitis transversa & 25 & $(11,9)$ \\
\hline HTLV 1 & 23 & $(11,0)$ \\
\hline Otras & 3 & $(1,4)$ \\
\hline Bacterianas & 28 & $(13,3)$ \\
\hline Mal de Pott & 14 & $(6,7)$ \\
\hline Mielitis-TBC & 9 & $(4,3)$ \\
\hline Meningoencefalomielitis & 2 & $(1,0)$ \\
\hline Otras & 3 & $(1,4)$ \\
\hline Degenerativas & 33 & $(15,7)$ \\
\hline Estenosis espinal & 16 & $(7,6)$ \\
\hline HNP & 14 & $(6,7)$ \\
\hline Otras & 3 & $(1,4)$ \\
\hline Neoplásicas & 29 & $(13,8)$ \\
\hline Schwanoma & 6 & $(2,9)$ \\
\hline Ependimoma & 5 & $(2,4)$ \\
\hline Neurinoma & 3 & $(1,4)$ \\
\hline Neurofibroma & 3 & $(1,4)$ \\
\hline Meningioma & 2 & $(1,0)$ \\
\hline Otras & 10 & $(4,8)$ \\
\hline Del desarrollo & 20 & $(9,5)$ \\
\hline Espina bifida - mielomeningocele & 20 & $(9,5)$ \\
\hline Vascular & 19 & $(9,0)$ \\
\hline Malformación arterio venosa & 17 & $(8,1)$ \\
\hline Otros & 2 & $(1,0)$ \\
\hline Idiopáticas & 12 & $(5,7)$ \\
\hline Siringomielia & 11 & $(5,2)$ \\
\hline Idiopática & 1 & $(0,5)$ \\
\hline Otras & 18 & $(8,6)$ \\
\hline Quiste & 5 & $(2,4)$ \\
\hline Aracnoiditis & 2 & $(1,0)$ \\
\hline Otras & 11 & $(5,2)$ \\
\hline TOTAL & 210 & $(100,0)$ \\
\hline
\end{tabular}

etiología infecciosa tuvieron nivel de lesión torácico, $54,5 \%$ con etiología degenerativa eran cervicales y $58,6 \%$ con etiología neoplásica tuvieron nivel de lesión torácico.

En las lesiones incompletas, referente a etiología se observó 81,0 \% infecciosas, 75,8 \% degenerativas y $72,4 \%$ neoplásicas. Clínicamente el tono muscular espástico fue el más frecuente, asociándose a etiología infecciosa $93,7 \%$, degenerativa $75,8 \%$ y neoplásica $79,3 \%$.

\section{DISCUSIÓN}

Los datos epidemiológicos respecto a la lesión medular en su mayoría, se refieren a la etiología traumática siendo muy difícil la recolección de estos datos en las no traumáticas ya que son tratadas por diferentes especialidades. El haber encontrado $27 \%$ de prevalencia de LMNT en nuestra institución es comparable con los resultados descritos en Perú con 29,5\% ${ }^{\left({ }^{(8)}\right.}$, en Bangladesh con el $28,0 \%{ }^{(3)}$; cifras diferentes a las descritas en España, donde alcanzó el 32,3\% ${ }^{(9)}$ y México donde alcanzó el $15,4 \%{ }^{(10)}$.

En el estudio, respecto a la edad, el grupo de 40 años o menos fue el más frecuente constituyendo el 66,2 \% con una media de 31,7 años, etapa altamente productiva de la vida, semejante a lo descrito en España $(38,4$ años) ${ }^{(9)}$ y menor a otros países como EE.UU. con una edad promedio de 61,2 años ${ }^{(11)}$, Australia con 61 años ${ }^{(12)} \mathrm{e}$ Italia con 55 años ${ }^{(13)}$. Asimismo, no se encontró diferencia en cuanto a sexo, como se informa en otros países donde predomina el sexo masculino como México que registra $65,2 \%{ }^{(10)}$, Italia $63,3 \%{ }^{(13)}$ y España $55,4 \%{ }^{(9)}$.

Tabla 3. Características clínicas según etiología no traumática en pacientes hospitalizados del INR (2000-2006)

\begin{tabular}{|c|c|c|c|c|c|c|}
\hline \multirow[b]{2}{*}{ Características } & \multicolumn{5}{|c|}{ Etiología no traumática } & \multirow{2}{*}{ TOTAL } \\
\hline & Infecciosa & Degenerativa & Neoplásica & Del desarrollo & Otros & \\
\hline \multicolumn{7}{|c|}{ Edad al inicio de lesión } \\
\hline $0 a<41$ & $54(68,4)$ & $6(18,2)$ & $21(72,4)$ & $20(100,0)$ & $38(77,5)$ & $139(66,2)$ \\
\hline $41-80$ & $25(31,6)$ & $27(81,8)$ & $8(27,6)$ & $0((0,0)$ & $11(22,5)$ & $71(33,8)$ \\
\hline \multicolumn{7}{|c|}{ Nivel de lesión al ingreso } \\
\hline $\mathrm{C} 2-\mathrm{C} 8$ & $12(15,2)$ & $18(54,5)$ & $12(41,4)$ & $0(0,0)$ & $11(22,4)$ & $53(25,2)$ \\
\hline $\mathrm{T} 1-\mathrm{T} 12$ & $59(74,7)$ & $11(33,4)$ & $17(58,6)$ & $11(55,0)$ & $37(75,5)$ & $135(64,3)$ \\
\hline L1 - L5 & $8(10,1)$ & $4(12,1)$ & $0(0,0)$ & $7(35,0)$ & $1(2,1)$ & $20(9,5)$ \\
\hline $\mathrm{S} 1-\mathrm{S} 5$ & $0(0,0)$ & $0(0,0)$ & $0(0,0)$ & $2(15,0)$ & $0(0,0)$ & $2(1,0)$ \\
\hline \multicolumn{7}{|c|}{ Tipo de lesión al ingreso* } \\
\hline$A$ & $15(19,0)$ & $8(24,2)$ & $8(27,6)$ & $10(50,0)$ & $11(22,4)$ & $52(24,8)$ \\
\hline B & $9(11,4)$ & $3(9,1)$ & $2(6,9)$ & $2(10,0)$ & $8(16,3)$ & $24(11,4)$ \\
\hline C & $29(36,7)$ & $12(36,4)$ & $14(48,3)$ & $4(20,0)$ & $22(44,9)$ & $81(38,6)$ \\
\hline $\mathrm{D}$ & $26(32,9)$ & $10(30,3)$ & $5(17,2)$ & $4(20,0)$ & $8(16,4)$ & $53(25,2)$ \\
\hline Espástico & $74(93,7)$ & $25(75,8)$ & $23(79,3)$ & $1(5,0)$ & $43(87,8)$ & $166(79,0)$ \\
\hline Flácido & $5(6,3)$ & $8(24,2)$ & $6(20,7)$ & $19(95,0)$ & $6(12,2)$ & $44(21,0)$ \\
\hline
\end{tabular}


El grado de instrucción que predominó en el presente estudio fue secundario $(41,9 \%)$ y nivel superior $(32,8 \%)$; solo encontramos un estudio realizado en México donde el $78,9 \%{ }^{(10)}$ tuvo grado de instrucción inferior al universitario.

Para el presente trabajo se utilizó la clasificación OIT y se agregaron dos grupos no incluidos: estudiantes y amas de casa. Los trabajadores representaron el 47,2 \%, llamando la atención el predominio de dependientes en todas las etiologías de LMNT, así como la elevada frecuencia de estudiantes $(25,2 \%)$ y amas de casa $(17,1 \%)$.

El alto nivel de pobreza encontrado (90,5 \%) implica una seria problemática social por lo cual este tratamiento integral, que por su naturaleza es costoso, viene siendo ampliamente subvencionado por el Estado. Esto agregado a las características geográficas de nuestro país hace aún más difícil la accesibilidad a este único centro a nivel nacional.

De los 210 casos estudiados se observó el predominio de las infecciones virales (24,3 \%) observándose una relación inversa a lo informado por España $(3,7 \%){ }^{(14)}$ por lo que sería conveniente realizar estudios posteriores al respecto.

Referente a las infecciones bacterianas por $M$. tuberculosis es importante mencionar lo descrito en España (29,6 \%), en relación a lo hallado en nuestro estudio en que casi toda la etiología bacteriana fue por tuberculosis. Los hallazgos de este estudio se diferencian de lo descrito para infecciosas por EE.UU. $(3,0 \%)^{(11)}$ y Australia (3 \%) ${ }^{(12)}$ donde no consignaron etiología precisa. El estudio corrobora que la etiología infecciosa en nuestro país estaría asociada con la condición socioeconómica de pobreza hallada en el $90,5 \%$ y que afecta una población en edad altamente productiva, lo que hace evidente la diferencia con los hallazgos de países desarrollados.

La etiología degenerativa hallada en el estudio (15,7 \%), es similar a Italia $(18,6 \%)^{(13)}$ y Australia $(17,9 \%)^{(12)}$. La neoplásica $(13,8 \%)$, es inferior a lo encontrado en Italia $(25 \%)^{(13)}$.

Los hallazgos de la investigación estarian relacionados con la distribución epidemiológica de países con problemas de pobreza. Aunque existen estudios que informan etiologías especificas como tuberculoma, hematomielia no traumática y sarcoidosis en médula espinal (15-18), el presente estuvo dirigido a encontrar causas generales de LMNT.

Para los investigadores era importante asociar la etiología con las variables sociodemográficas teniendo en cuenta las características de la población que atendemos y más aún no habiéndose encontrado mayores informes. Las etiologías infecciosa y neoplásica predominaron en el grupo de mujeres hasta 40 años, la degenerativa en varones mayores de 40 años. En estado civil y etiología solo observamos mayor frecuencia de casados en las degenerativas. Asimismo, respecto al grado de instrucción y etiología, los resultados fueron dispares.

Al comparar las LMNT y nivel de lesión toráxico de nuestro estudio $(64,3 \%)$, con lo descrito por otros países se evidenció gran diferencia con México $(11,1 \%){ }^{(10)}$ y Bangladesh $(25,0 \%){ }^{(3)}$. En los niveles cervicales, México informó un $14,0 \%$, a diferencia del presente estudio con $25,2 \%$. El hallazgo de $75,2 \%$ de los pacientes con lesión incompleta $(\mathrm{B}, \mathrm{C}, \mathrm{D})$ y de etiología predominantemente infecciosa implica la necesidad de una intervención primaria oportuna. Este resultado es similar a México $(69,6 \%)$ y Australia (88,0 \%). Dentro de las lesiones incompletas el tipo $\mathrm{C}$ fue el más frecuente. Asimismo predominó el tono muscular espástico.

El estudio tuvo algunas limitaciones, dado que se realizó en una muestra no representativa de la población de Perú, no es posible realizar una extrapolación de los datos $y$, al ser necesaria la prevención respecto a la etiología, existe la inquietud de los investigadores de realizar un estudio de mayor magnitud o multicéntrico.

En conclusión, identificamos que las causas de LMNT son mayormente infecciosas, en personas en edad productiva, con grado de instrucción medio-superior, la mayoría desocupados, en situación de pobreza y con características clínicas de lesiones incompletas, con todas las implicancias que origina la secuela de una lesión medular.

\section{Contribuciones de autoría}

AQG participó en la concepción y diseño del trabajo, recolección/obtención de resultados, análisis e interpretación de datos, redacción y revisión del manuscrito, aprobación de versión final, obtención de financiamiento. RSE y MMR participaron en la concepción y diseño del trabajo, recolección/obtención de resultados, análisis e interpretación de datos, redacción y revisión del manuscrito, aprobación de versión final. CKG participó en recolección/obtención de resultados, revisión del manuscrito y aprobación de la versión final.

\section{Conflictos de interés}

Los autores declaran no tener ningún conflicto de interés. 


\section{Fuentes de financiamiento}

Este trabajo fue financiado por el Instituto Nacional de Rehabilitación

\section{REFERENCIAS BIBLIOGRÁFICAS}

1. Gibson CJ. Overview of spinal cord injury. Phys Med Rehabil Clin N Am. 1992;3(4):699-709.

2. Mazaira J, Labanda F, Romero J, García ME, Gambarruta C, Sánchez A, et al. Epidemiología de la lesión medular y otros aspectos. Rehabilitación (Madr). 1998;32:365-72.

3. Hoque MF, Grangeon C, Reed K. Spinal cord lesions in Bangladesh: an epidemiological study 1994 - 1995. Spinal Cord. 1999;37(12):858-61.

4. Instituto Nacional de Rehabilitación, Departamento de Investigación, Docencia y Rehabilitación Integral en Lesiones Medulares. Daños Trazadores. Bellavista, Callao: Instituto Nacional de Rehabilitación; 2004.

5. Martí Massó JF, Martínez Zabaleta M. Enfermedades no degenerativas de la médula espinal: concepto, clasificación sindrómica, manifestaciones clínicas y estrategia diagnóstica. Medicine. 2003;8(99):5321-6.

6. Taricco MA. Etiologia das Lesoes Medulares. En: Greve $\mathrm{JM}$, Casalis ME, Barros TE, editores. Diagnóstico e Tratamento da Lesao da Medula Espinal. Sao Paulo: Editorial Roca; 2001.

7. Ditunno JF, Young WS, ed. International Standards for Neurological and Functional Classification of Spinal Cord Injury revised 1992. Buffalo: ASIA/ IMSOP; 1992.

8. Vasquez J. Estudio de prevalencia de lesiones medulares en el Instituto Nacional de Rehabilitación 1999-2002 [Tesis para optar el grado de Magister en Medicina]. Lima, Perú. Universidad Peruana Cayetano Heredia. 2007.

9. García AM, Méndez JL, Bataller EB, Sánchez J, Miranda G, Álvarez C. Epidemiología de la lesión medular en la provincia de Las Palmas. Rehabilitación (Madr). 2003;37(2):86-92.
10. Pérez $R$, Martín del Campo $S$, Renán $S$, Durán $S$. Aspectos epidemiológicos de la lesión medular de la población del Centro Nacional de Rehabilitación. Revista Mexicana de Medicina Física y Rehabilitación. 2008;20:7482

11. Citterio A, Franceschini M, Spizzichino L, Reggio A, Rossi B, Stampacchia G. Nontraumatic spinal cord injury: an italian survey. Arch Phys Med Rehabil. 2004 85(9):14837.

12. McKinley WO, Seel RT, Hardman JT. Nontraumatic spinal cord injury: incidence, epidemiology, and functional outcome. Arch Phys Med Rehabil. 1999;80(6):619-23.

13. New PW, Rawicki HB, Bailey MJ. Nontraumatic spinal cord injury: demographic characteristics and complications. Arch Phys Med Rehabil. 2002;83(7):996-1001.

14. Morillo-Leco G, Alcaraz-Rousselet MA, Díaz-Borrego P, Sáenz-Ramírez L, Artime C, Labarta-Bertol C. Características clínicas de la lesión medular de causa infecciosa. Rev Neurol. 2005;41(4):205-8.

15. Kalita J, Mistra UK. Intramedullary cervical tuberculoma. Spinal Cord. 1999;37(4):297-8.

16. Karavelis A, Foroglou G, Petsanas A, Zarampoukas T. Spinal cord dysfunction caused by non-traumatic hematomyelia. Spinal Cord. 1996;34(5):268-71.

17. Ku A, Lachmann E, Tunkel R, Nagler W. Neurosarcoidosis of the conus medullaris and cauda equina presenting as paraparesis: case report and literatura review. Paraplegia. 1996;34(2):116-20.

18. Saleh S, Saw C, Marzouk K, Sharma O. Sarcoidosis of the spinal cord: literature review and report of eight cases. J Natl Med Assoc. 2006;98(6):965-76.

Correspondencia: Asencio Quintana Gonzales

Dirección: Edmundo Pini 382. San Martin de Porres. Lima,

Perú.

Teléfono: (51) 995055829

Correo electrónico: asencioqg@hotmail.com

\section{Consulte la versión electrónica de la Revista Peruana de Medicina Experimental y Salud Pública en}

\section{wWW.scopus.com}

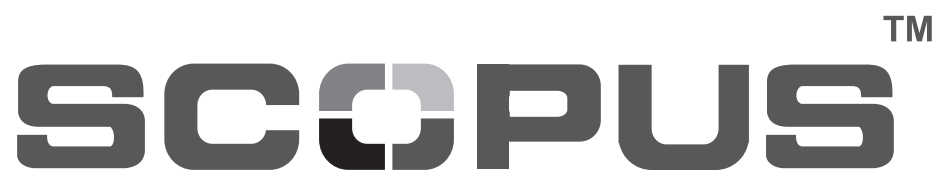

